Supporting Information

\title{
Time-Resolved Product Analysis of
}

\section{Dimethylether-to-Olefins Conversion on}

\section{SAPO-34}

\author{
Alfred Haas, Christoph Hauber, and Marius Kirchmann* \\ hte GmbH, the high throughput experimentation company, 69123 Heidelberg, Germany \\ E-mail: marius.kirchmann@hte-company.de
}




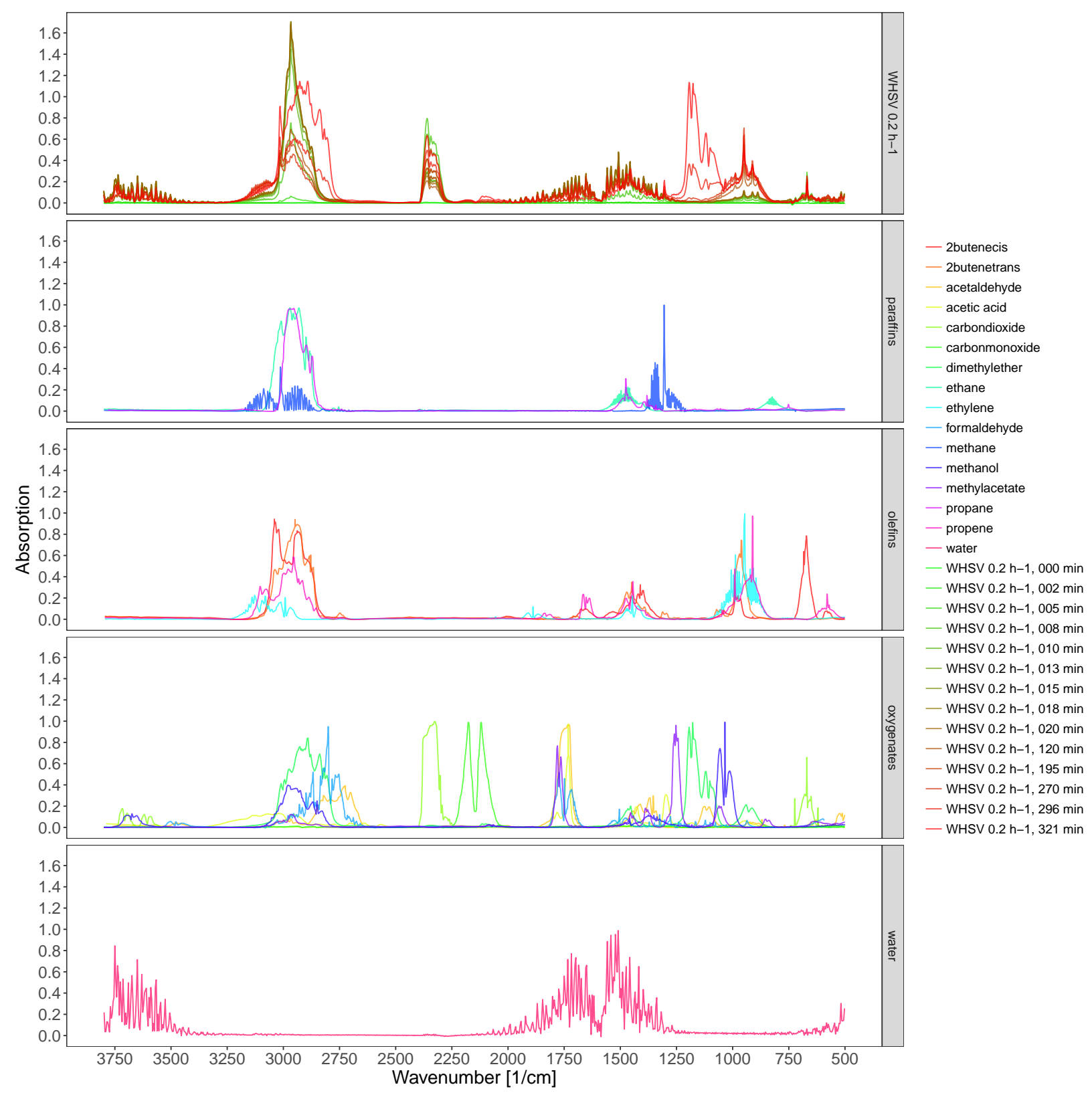

Figure S1: Top: IR spectra from the measurements at WHSV $=0.2 \mathrm{~h}^{-1}$ and $400^{\circ} \mathrm{C}$. Lower: spectra obtained from the NIST database for paraffins, olefins, potential oxygenates and water. 


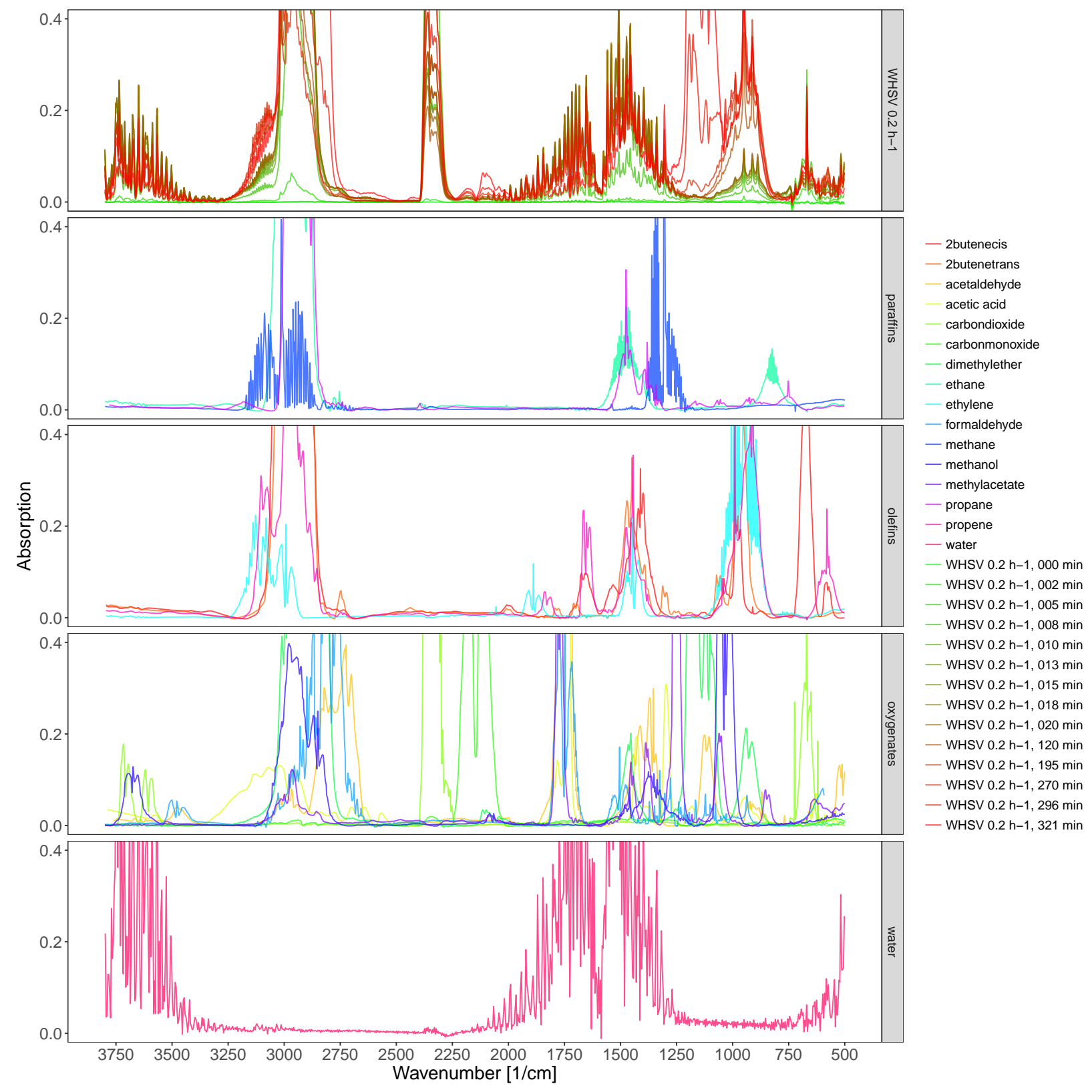

Figure S2: Enlargement of former figures. Top: IR spectra from the measurements at WHSV $=0.2 \mathrm{~h}^{-1}$ and $400^{\circ} \mathrm{C}$. Lower: spectra obtained from the NIST database for paraffins, olefins, potential oxygenates and water. 


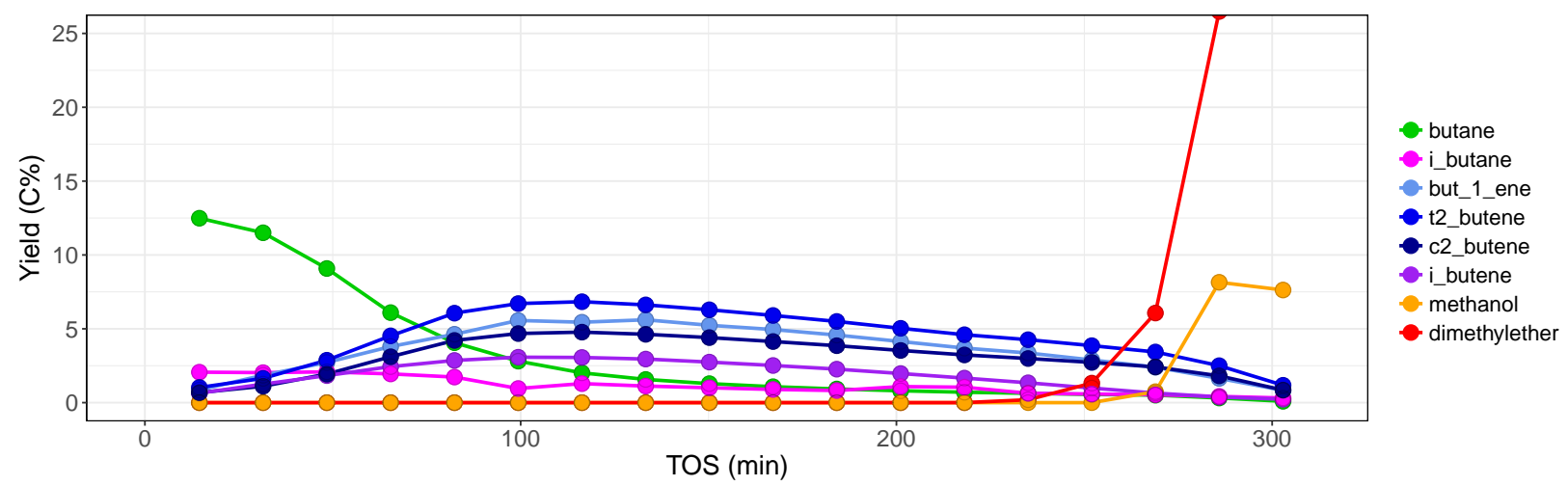

Figure S3: Detailed C4 isomer distribution obtained by GC at WHSV $=0.2 \mathrm{~h}^{-1}$ and $400^{\circ} \mathrm{C}$.

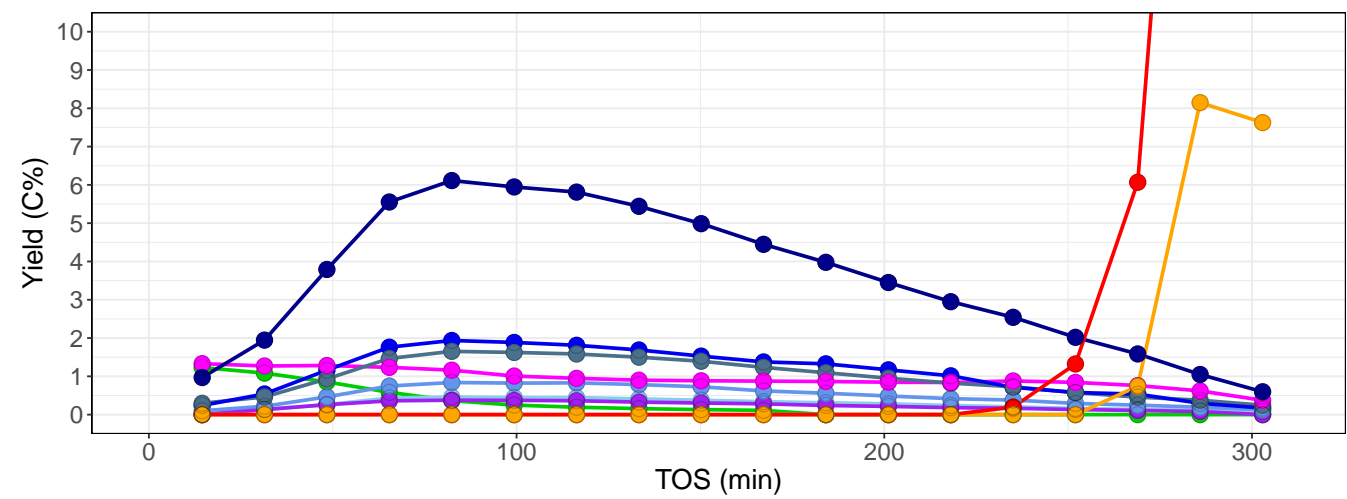

- n_pentane

- i_pentane

- pent 1_ene

c_pent_2_ene

t_pent_2_ene

- methyl_2_but_1_ene

- methyl_2_but_2_ene

- methyl_3_but_1_ene

methanol

- dimethylether

Figure S4: Detailed C5 isomer distribution obtained by GC at WHSV $=0.2 \mathrm{~h}^{-1}$ and $400^{\circ} \mathrm{C}$.

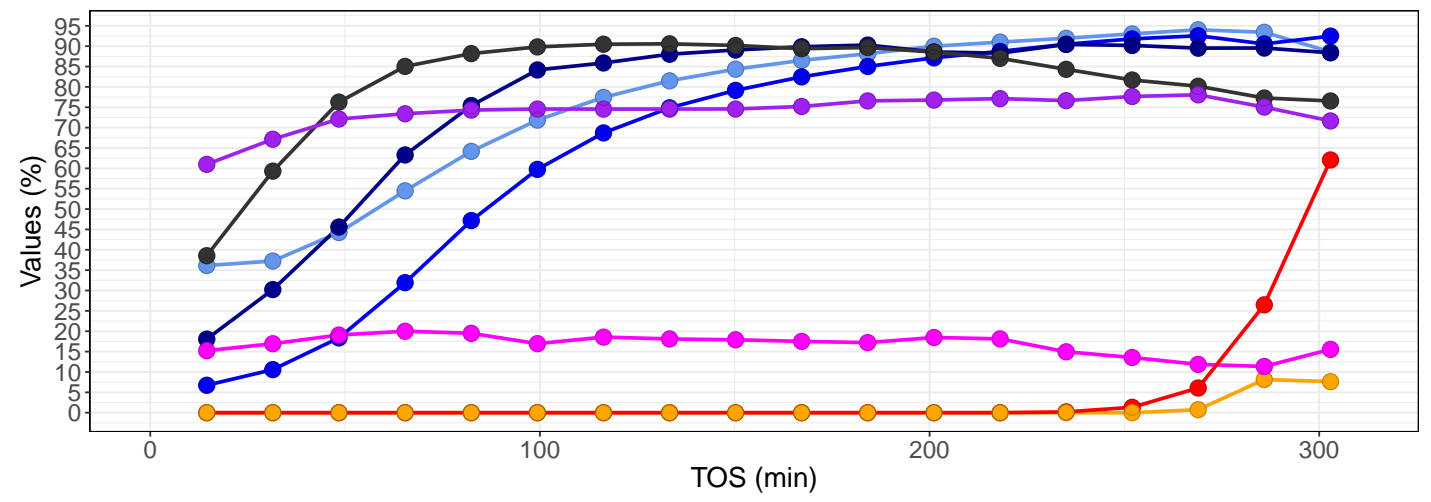

C2_olefinicity

- C3_olefinicity

- C4 olefinicity

- C5_olefinicity

- C4_DOB

- C5_DOB

methanol

- dimethylether

Figure S5: C2-C5 olefinicities and degree-of-branching (DOB) obtained by GC at WHSV = $0.2 \mathrm{~h}^{-1}$ and $400^{\circ} \mathrm{C}$. 


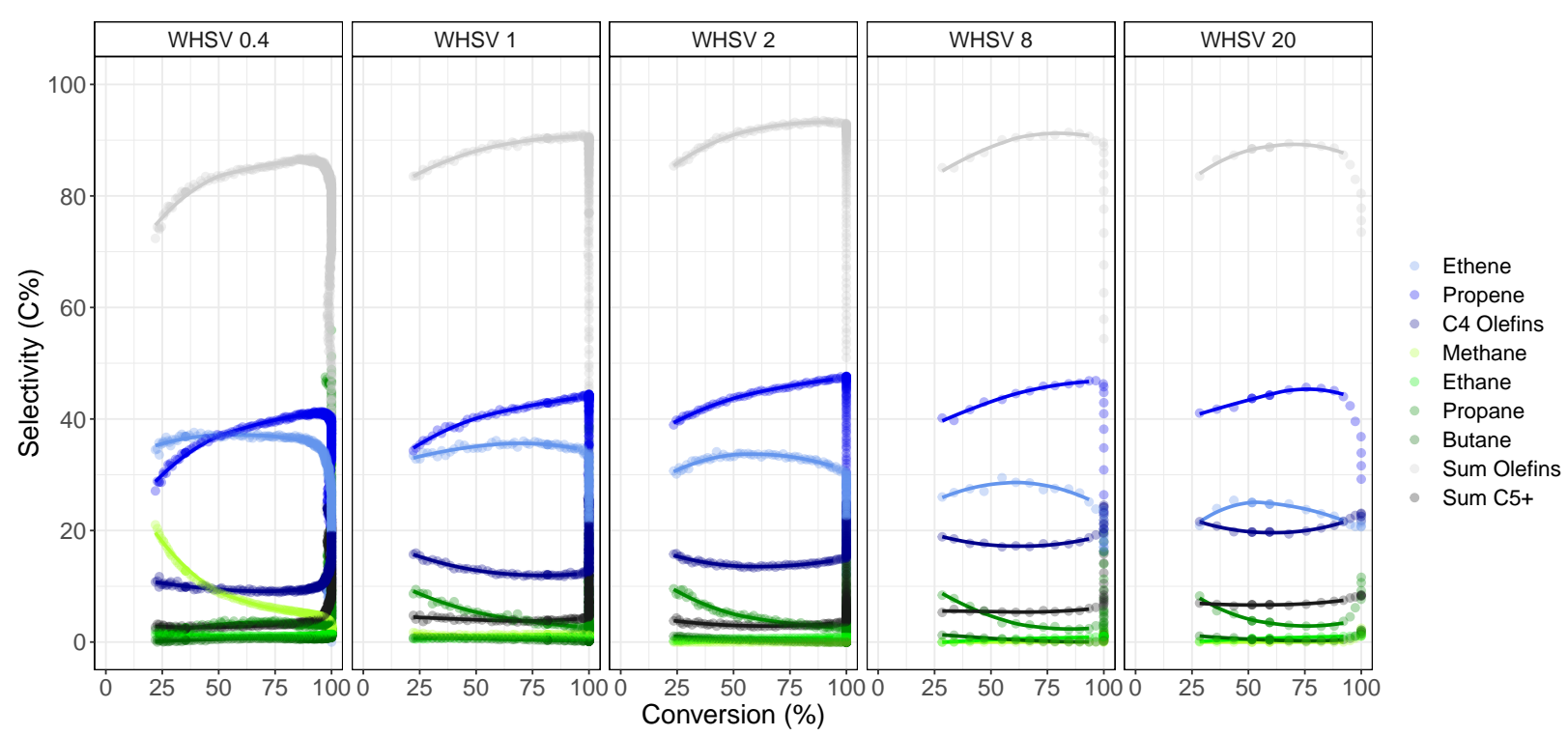

Figure S6: Selectivities versus conversion obtained by FTIR at WHSV $=0.4-20 \mathrm{~h}^{-1}$ and $400^{\circ} \mathrm{C}$.
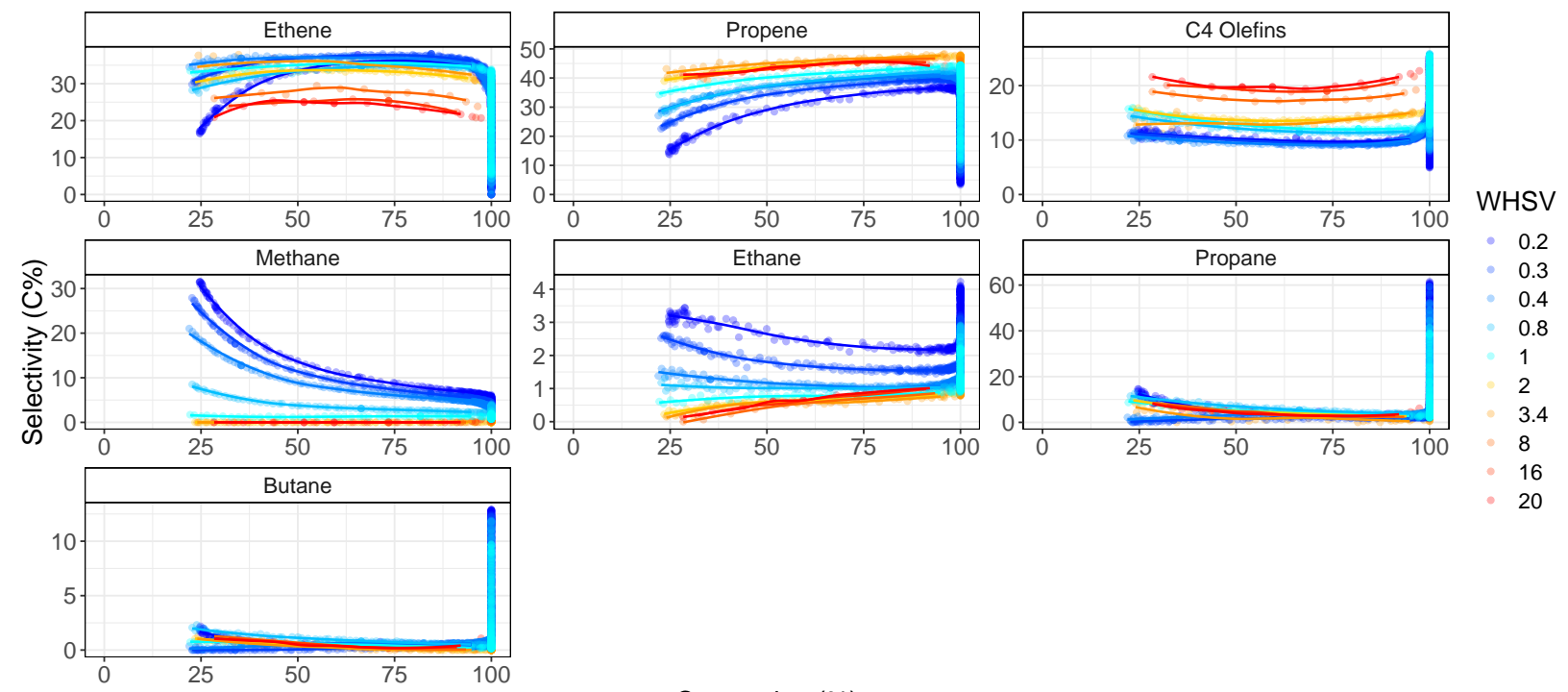

Conversion (\%)

Figure S7: Selectivities versus conversion obtained by FTIR at WHSV $=0.2-20 \mathrm{~h}^{-1}$ and $400^{\circ} \mathrm{C}$ for different compounds. 


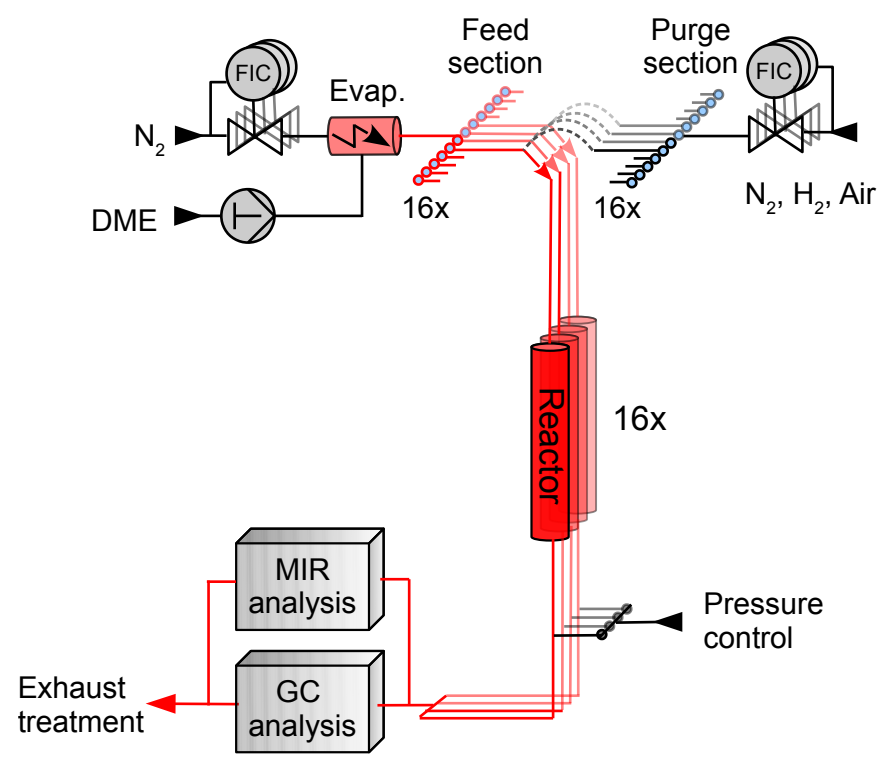

Figure S8: Simplified process scheme of a 16-fold high throughput unit. 


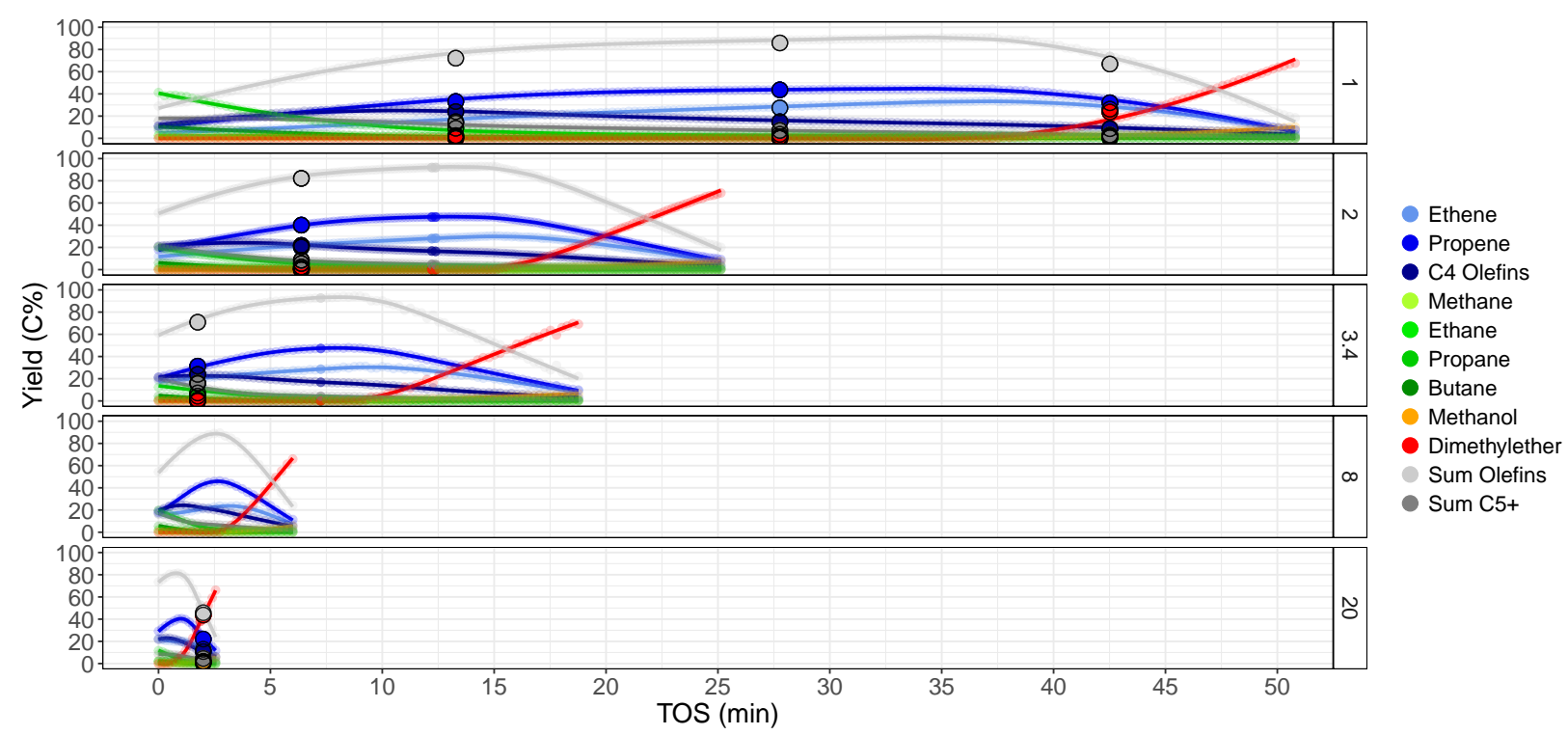

Figure S9: Product distribution for different severities from $1-20 \mathrm{~h}^{-1}$ at $400^{\circ} \mathrm{C}$ with vertical split by severity. The big symbols show the GC data, whereas the smaller symbols show the predicted data from the FTIR spectra. The solid line indicates a local regression (LOESS) for the FTIR data.

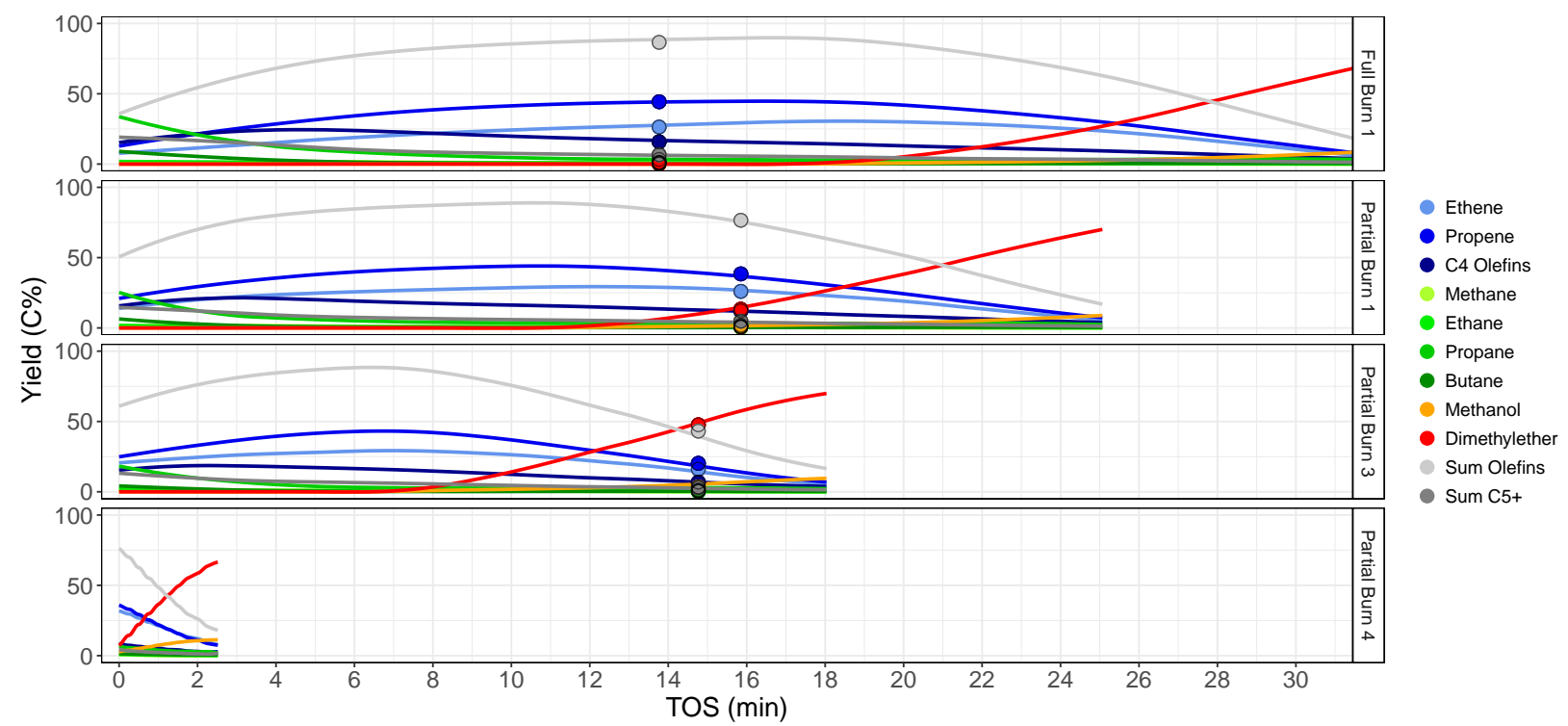

Figure S10: Product distribution at $\mathrm{WHSV}=1.6 \mathrm{~h}^{-1}$ at $400^{\circ} \mathrm{C}$ with vertical split by completeness of coke burn. The big symbols show the GC data, whereas the smaller symbols show the predicted data from the FTIR spectra. The solid line indicates a local regression (LOESS) for the FTIR data. 
Table S1: Details on partial coke burn.

\begin{tabular}{llll}
\hline $\begin{array}{l}\text { Length of coke burn } \\
\text { min }\end{array}$ & $\begin{array}{l}\text { Coke on cat burned } \\
\text { wt\% }\end{array}$ & $\begin{array}{l}\text { Percentage burned } \\
\%\end{array}$ & $\begin{array}{l}\text { Breakthrough time } \\
\text { min }\end{array}$ \\
\hline 100 & 3 & 100 & 18.5 \\
5 & 1.47 & 49 & 0 \\
10 & 1.8 & 59 & 9 \\
15 & 2 & 67 & 10 \\
20 & 2.16 & 72 & 14.5 \\
\hline
\end{tabular}

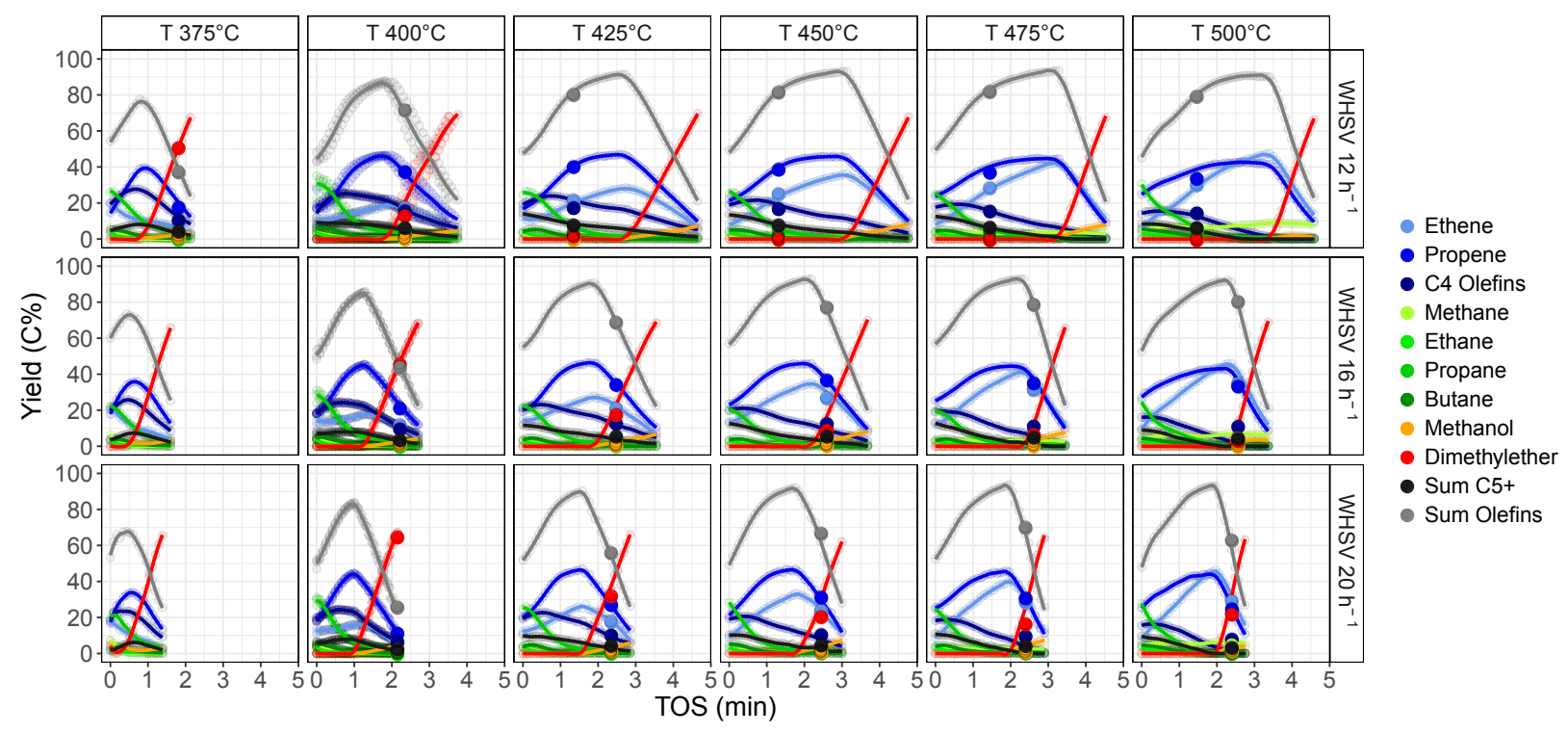

Figure S11: Product distribution collected at different temperatures and WHSVs, horizontal split by temperatures, vertical split by WHSV. The condition at $400^{\circ} \mathrm{C}$ and $\mathrm{WHSV}=12$ $\mathrm{h}^{-1}$ was used as reference condition and includes multiple oberlying measurements. 